\title{
Chlamydia: A Disease Without A History
}

\section{Document Version}

Final published version

Link to publication record in Manchester Research Explorer

\section{Citation for published version (APA):}

Worboys, M. (2019). Chlamydia: A Disease Without A History. In S. Szreter (Ed.), The Hidden Affliction: Sexually Transmitted Infections and Infertility in History (pp. 153-183). University of Rochester Press.

\section{Published in:}

The Hidden Affliction: Sexually Transmitted Infections and Infertility in History

\section{Citing this paper}

Please note that where the full-text provided on Manchester Research Explorer is the Author Accepted Manuscript or Proof version this may differ from the final Published version. If citing, it is advised that you check and use the publisher's definitive version.

\section{General rights}

Copyright and moral rights for the publications made accessible in the Research Explorer are retained by the authors and/or other copyright owners and it is a condition of accessing publications that users recognise and abide by the legal requirements associated with these rights.

\section{Takedown policy}

If you believe that this document breaches copyright please refer to the University of Manchester's Takedown Procedures [http://man.ac.uk/04Y6Bo] or contact uml.scholarlycommunications@manchester.ac.uk providing relevant details, so we can investigate your claim.

\section{OPEN ACCESS}




\title{
Chapter Five
}

\section{Chlamydia}

\section{A Disease without a History}

\author{
Michael Worboys
}

Since the late 1990s chlamydia has been the most commonly reported sexually transmitted infection (STI) in Europe and the United States. ${ }^{1}$ The infection is caused by the bacterium Chlamydia trachomatis (C. trachomatis), and its common name follows a pattern established in the late nineteenth century, where an infection is named after its causal pathogen. ${ }^{2}$ In England in 2017 there were just over 203,116 new diagnoses, compared to 7,137 of syphilis and 44,676 of gonorrhea. ${ }^{3}$ Over 126,000 of the chlamydia diagnoses were made by the National Chlamydia Screening Programme, which targets fifteen to twenty-four-year-olds because the disease, which is asymptomatic in 80 percent of females infected, can lead to infertility due to blocked fallopian tubes. The disease has been equally prevalent in men, and while there has been an expectation of similar effects on seminal vesicles, there is as yet no evidence of a strong correlation between infection and male infertility. ${ }^{4}$ The program began in 2004 , after a decade in which the reported incidence of chlamydia grew rapidly, and journalists picked up on these reports warnings of a "fertility timebomb." Public health concern about the disease also derived from its seeming novelty and to uncertainties over its pathology. Chlamydia first became recognized as a specific STI in the 1970s, but it took until 1988 for it to become notifiable. Newly diagnosed cases were reported only routinely in STI statistics from 1990, when there 
were 34,000 new diagnoses. The number began to rise steeply after 1995, reaching 100,000 in 2003. The growing incidence seemed to public health officials to be both "true" and "questionable." The increase seemed to be true because of the increase in the number of couples seeking fertility treatment, plus the pattern of chlamydia's spread seemed to fit with a view that young people were having a greater number of sexual partners. ${ }^{6}$ Yet it was also considered questionable because advances in treatments for infertility, notably in vitro fertilization, led to increased demand for services; also more and more cases of chlamydia were identified by improvements in the sensitivity and specificity of testing methods.

Chlamydia as an STI is a disease without a history in two senses: first, it became a clinical entity only in the 1970s, and, second, its medical and social history has still to be written-an absence this chapter begins to correct. ${ }^{7}$ Its seeming novelty in the 1970s prompts the question, Was it an infection newly arrived in humans, or had it always been present and was now being recognized for the first time ${ }^{8}$ This is a question that can only be answered, not by a medical historian but by investigations of past populations by epidemiologists, pathologists, and, perhaps most likely, by archaeologists using genomics. However, medical publications and oral testimony reveal that doctors in the 1970s were confident that chlamydia was not a new disease. They believed this new ailment had actually been around for decades and probably centuries, being one, probably the most important, of the infections that had been hidden in that most unsatisfactory disease entity nongonococcal urethritis (NGU), also called nonspecific urethritis (NSU). NGU was defined by what it was not. It required a laboratory diagnosis and had been invented by clinicians when, in patients with gonorrhea-like symptoms, the gonococcus could not be found in genital discharges. NGU was unaffected by antibiotics used to treat gonorrhea, which became further negative diagnostic confirmation. The laboratory was also crucial to the creation of chlamydia as a clinical entity, which came from the development of new techniques in the 1960s and 1970s, which enabled doctors to differentiate NGU into component infections: C. trachomatis, lymphogranuloma venereum (LGV, which was later shown to be caused by different strains of $C$. trachomatis from those causing chlamydia), Mycoplasma genitalium, and trichomoniasis (caused by the protozoan Trichomonas vaginalis). ${ }^{9}$

While there is little or no historical scholarship on chlamydia as an STI, there are some studies of the bacterium's other pathological effects, the eye infection trachoma, caused by the same bacterium; and psittacosis, a type of pneumonia caused by Chlamydia psittaci, which bird fanciers catch from infected animals. ${ }^{10}$ Trachoma is the leading cause of infectious blindness in 
the world and now the subject of control efforts by several agencies. ${ }^{11}$ There are short histories of NGU, written by STI specialists, which discuss chlamydia along with the other diseases into which the entity has now been broken down; however, these tend to be presentist and teleological, portraying this differentiation as inevitable. ${ }^{12}$ The great challenge for historians writing the history of any disease, but especially one that is newly identified, is captured in Charles Rosenberg's provocative claim that "a disease does not exist until we have agreed that it does, by perceiving, naming, and responding to it." ${ }^{13}$ Or, as Peter Sedgwick put it, "There are no illnesses or diseases in nature"; rather, illnesses and diseases are the labels and action humans construct about the experiences, meanings, and implications of natural phenomena. ${ }^{14}$ Rosenberg qualifies the radical relativist implications of his statement by prefacing it with "in some ways" and applies it only to disease as a "social phenomenon." His realist stance is clear in his view that disease is also a "biological event little modified by the particular context in which it occurs." ${ }^{15}$ In this chapter I chart how the social and the biological were brought together by different historical actors to coproduce both NGU and chlamydia. For example, one distinctive feature of the biology of chlamydia - that it is largely symptomless in women-shaped social responses and clinical interventions, and these altered the epidemiology and perhaps the pathology of the infection. Indeed, STIs doctors since the 1990s have debated whether early antibiotic treatment has actually worsened the problem, leading to "arrested" immune responses and persistent vulnerability to infection. ${ }^{16}$

In this chapter I follow the more radical version of Rosenberg's approach, with a narrative that details how chlamydia as a disease entity was constructed rather than discovered. I show how it was coproduced in the interactions of microbes, patients, doctors, scientists, public health agencies, and other actors, in the context of changing laboratory technologies, attitudes toward STIs and infertility, and health policies. My focus is on Britain, but the story was similar in other industrialized countries and increasingly internationally owing to shared research and comparisons of national policies. I begin with the construction of another clinical entity, nongonococcal urethritis, in the 1930s, which, as the name indicates, was closely linked to medical and social ideas, practices, and policies for gonorrhea. A key difference was that NGU was framed as a condition that affected only men and, unlike gonorrhea, was not associated with ill health and sterility in women. ${ }^{17} \mathrm{NGU}$ was unusual in being defined by what it was not and, for the time, in having its positive diagnosis dependent on laboratory testing. 
I next consider medical and social responses to the growing incidence of NGU in men, from 1951, when new cases were first reported, to the early 1970s. In Britain gonorrhea lost its status as the most prevalent venereal disease to NGU in 1975, prompting new interest in the latter. The incidence of chlamydia in women had been first reported in 1971 and soon became linked to infertility, pelvic inflammatory disease (PID), and chronic ill health. The manner in which chlamydia, as a component of NGU, changed from a one- to two-sex disease echoed how the pathology of gonorrhea was remade in the early twentieth century. ${ }^{18} \mathrm{My}$ focus in this chapter is on the disease in women, but from the mid-1990s doctors reported that chlamydia could lead to infertility in men, albeit at a lower rate, by damaging sperm and causing epididymitis (and this has not since been confirmed). ${ }^{19}$ Finally, I discuss the changing profile of chlamydia from the mid-1970s to the 2010s, the key feature of which was the public health focus on the infection in women, reversing the previous situation. Its incidence in women became a major public health concern, and STI specialists and gynecologists began to talk about its role in creating an infertility crisis. The arrival of HIV/AIDS pushed these concerns aside until the late 1990s, when they were pushed to the fore again and once more linked to fertility and PID. Since then a number of initiatives have been developed to determine the level of incidence in young women, the most vulnerable group, and develop preventive and therapeutic policies and programs.

\section{Gonorrhea and Nongonococcal Urethritis, 1900-1945}

Until the late nineteenth and early twentieth century, gonorrhea was a disease understood to affect mainly men. It was a specific type of urethritis, with a characteristic discharge from the penis and inflammation of the genitourinary system caused by the bacterium Neisseria gonorrhoeae. The infection typically "cleared up" in three or four weeks, though in many cases there were longterm effects, the most common being inflammation of the joints. Gonorrhea was thought to be less common and less serious in women. However, doctors were clear that women could harbor the gonococcus without symptoms, from the number of babies whose eyes were infected at birth and developed ophthalmia neonatorum, then a major cause of blindness. ${ }^{20}$ Some estimates are that a third of all blindness in the nineteenth-century era was due to this infection, a proportion that fell from the 1890s, when it became more common but by no means universal to irrigate the eyes of newborn babies with dilute silver nitrate. ${ }^{21}$ The medical and social recognition that gonorrhea 
could be serious in women came from work of gynecologists and pathologists from the 1890s and the campaigning of public health doctors and women's groups in the first decades of the twentieth century, with no one more active than Christabel Pankhurst. She set out her claims in The Great Scourge and How to End It, published in 1913, which is now best known for its seeming invitation for suffragists to start a "Sex War," but it also had a lot to say about women's health. ${ }^{22}$ The "Great Scourge" was venereal disease, but, unusually for the time, Pankhurst gave more space to gonorrhea than syphilis and special attention in a chapter on "The Dangers of Marriage." She maintained that male doctors had concentrated on syphilis, the disease that affected mostly their sex, neglecting gonorrhea, the most serious venereal disease in women. Indeed, she stressed that men escaped lightly from gonorrhea with a short-lived, local infection, while women suffered long-term complications, children were threatened by blindness, and the race weakened by a falling birthrate, due to chronic ill health that led to women having fewer or no children. ${ }^{23}$ The principal consequence was salpingitis: "an attack of acute suppurating pelvic peritonitis with a background of genital symptoms due to acute suppuration of one or both Fallopian tubes." ${ }^{24}$ In newly married women gynecologists termed it "honeymoon appendicitis," but for those with the condition its consequences could be anything but short-term, with lifelong chronic ill health common. As Anne Hanley has shown, many doctors linked venereal diseases with infertility, but there was no consensus on their importance or what to do. ${ }^{25}$ The aim of treatments, when tried, was to prevent the spread of the infection to the abdominal cavity (what would now be termed PID) and restore function to the fallopian tubes where possible, which often required surgery.

Contemporary medical opinion was that Pankhurst had exaggerated the incidence of gonorrhea, but that "the serious nature of the sequelae . . is not exaggerated, and it is probably true that they are, on the whole, more serious in women than in men." ${ }^{26}$ In the evidence given to the Royal Commission of Venereal Disease, doctors agreed that gonorrhea was responsible for around a third of all sterility, affecting both men and women. Similar estimates of the impact of gonorrhea could be found in the other industrialized countries. ${ }^{27}$ In his book on Gonorrhea in Women, published in 1913, the US gynecologist Charles Norris reported "that 30 per cent, to 50 per cent, of all childless marriages are directly caused by gonorrhoea." ${ }^{28}$ Interestingly, some doctors suggested that the by then relative rarity of ophthalmia neonatorum in obstetric practice was as much due to (increased) female sterility produced by gonorrhea as much as it was to disinfection of babies' eyes. ${ }^{29}$ Through the 1920s and 1930s medical views on infection and sterility divided on gender 
lines: the condition in men was linked primarily to epididymitis caused by gonorrhea, while in women it was associated with infection of the cervix, salpingitis, and pelvic inflammation, as well as puerperal sepsis. ${ }^{30}$ In fact, the gonococcus was not the only pathogen associated with sterility: staphylococci, streptococci, the tubercle bacillus, and as yet unspecified microorganisms such as viruses (first identified in this period) were also all implicated. In 1937 Maeve Kenny, who worked at Queen Charlotte's Maternity Hospital, Hammersmith, published an article on the aftereffects of puerperal infection. ${ }^{31}$ Her study was of a hundred women treated in the isolation block of Queen Charlotte's, and her principal finding was "that sterility is a prominent sequel to puerperal infection," though she could only speculate on how the disease affected women's reproductive organs and fertility.

Kenny had pioneered, with Leonard Colebrook, the introduction of sulfonamide drugs, which were transforming the prognosis of women with puerperal sepsis and impacting maternal mortality. ${ }^{32}$ Sulfonamides also transformed the treatment of gonorrhea. ${ }^{33}$ The sex of the patients in the early trials is rarely mentioned, but the implication is that they were principally men, as success was judged by the absence of clinical symptoms. ${ }^{34}$ The improvement in the treatment of gonorrhea, along with the prognoses for patients with syphilis, due to Salvarsan and its derivatives, meant that at the end of the 1930s doctors were more and more challenged by patients with chronic, nonspecific venereal disease and its effects. In a letter to the Lancet in September 1937, A. Malcolm Simpson argued, "It seems obvious that the syphilis department of a V.D. clinic should be divorced from the gonorrhoeal one; the director of the former having special experience in dermatology, cardiology, and neurology, and that of the latter in genito-urinary surgery and gynaecology." 35

The particular success of sulfonamides in the treatment of gonorrhea revealed the number of patients at venereal disease clinics who had "genito-urinary (non-gonococcal) infections." ${ }^{36}$ Arthur Harkness, a South African who had qualified at Guy's Hospital in 1914 and then served in the Royal Navy Reserve, had labeled this a disease entity in 1933. ${ }^{37}$ Harkness's NGU diagnosis depended on negative bacteriological results from patients with the symptoms of gonorrhea, a group that sulfonamide treatment further differentiated. ${ }^{38}$ Apparently, Harkness found NGU only in men, with women mentioned only as sources of male infection; indeed, its sex specificity was another marker of NGU's distinctiveness from gonorrhea. ${ }^{39}$

The first published exploration of a link between NGU and trachoma was in 1939, in a review by Lawrence Harrison, Britain's leading venereologist; and Werner Worms, a German émigré doctor. ${ }^{40}$ Their focus was on "Waelsch 
urethritis," a type of urethritis first identified in 1901, and on the presence of so-called inclusion bodies in a number of inflammatory venereal conditions: trachoma, inclusion blennorrhoea, various types of conjunctivitis, LGV, and NGU. Trachoma had attracted the attention of ophthalmologists in the 1920s, with the International Organization against Trachoma founded in $1930 .^{41}$ The agency was created around two appeals: first, the prevention of blindness in infants and, second, halting its spread from the tropics; indeed, trachoma had been made a notifiable disease in Glasgow in 1914 because of fears of its importation..$^{42}$ At its meeting in 1935, the organization's president maintained that its work "may deservedly be placed among the campaigns against cancer and tuberculosis." 43 There was agreement among ophthalmologists that trachoma was infectious and was associated with intracellular or inclusion bodies that had been first observed in 1907 by Ludwig Halberstaedter and Stanilaus von Prowazek. These became known as TRIC agents (from trachoma inclusion conjunctivitis), and their presence within cells (intracellular) led many bacteriologists to place them in the new category of viruses; but there were other possibilities: phagocytosed gonococci or rickettsia—intracellular bacterial pathogens. ${ }^{44}$ Around 1930 similar inclusion bodies were reported in cases of psittacosis, a disease of birds that had spread to humans in sporadic outbreaks in the 1920s and early 1930s. ${ }^{45}$

In the 1940s textbooks on venereal diseases began to include a chapter on "Other Conditions." Angus McLachlan's Handbook of Diagnosis and Treatment of Venereal Diseases, published in 1944, discussed eight such diseases: balanoposthitis, LGV, NGU, thrush, trichomoniasis, ulcus actum vulvae, vaginitis, vulvovaginitis, and warts. He wrote that the most puzzling was NGU, which he also termed "simple urethritis" and "post-gonococcal urethritis" (PGU). ${ }^{46}$ Clinicians suggested three causes; typically, each was morally loaded: (1) septic and opportunistic bacterial infection, linked to sodomy or intercourse during menstruation; (2) chemical irritation due to the use of contraceptives; and (3) physical trauma caused by sexual excess. ${ }^{47}$ The idea that women were carriers and the primary source of the infection was implied in 1942 by Gerald McElligott, a Royal Air Force medical officer, when he wrote, after a survey of men, that "I have not recently had the opportunity of examining many female consorts." Nonetheless, he suggested that infection from women was likely to be facilitated by previous venereal infection; unclean and careless methods of douching; the growing use of internal menstrual tampons; and previous instrumental interference with the cervix, in other words, induced abortion. ${ }^{48}$ 


\section{NGU Established, 1945-1975}

Investigations of NGU had flourished during World War II because of the attention given to venereal diseases in the armed services and the success of sulfonamides and then penicillin in treating gonorrhea. ${ }^{49}$ In January 1948 the first report of the newly formed World Health Organization's Expert Committee on Venereal Diseases drew attention to a number of genitourinary infections of "ill-defined origin," including NGU, and called for more studies of them. ${ }^{50}$ The findings were based mostly on evidence submitted by Harkness, which showed that NGU was common worldwide. Two years later Harkness published a book titled Non-gonococcal Urethritis, which reviewed the literature on all manner of genitourinary conditions and concluded that NGU was a specific condition, though one for which he was unable to specify a microbial cause or diagnostic test. ${ }^{51} \mathrm{He}$ mentioned C. trachomatis as a possible factor, though he was unclear whether it was a primary cause, secondary consequence, or coincidental contaminant. Harkness's work was largely behind the inclusion of NGU in British statistics of new cases of venereal disease from $1951 . .^{52}$

In 1954 Harkness and Claude Nicol, the author of a standard textbook on venereal diseases, spoke on NGU at a joint meeting of the Medical Society for the Study of Venereal Diseases and of the Metropolitan Branch, Society of Medical Officers of Health. ${ }^{53}$ The discussion after their talk revealed that doctors remained dissatisfied with accounts of NGU's causation but agreed that bacteria were likely the primary or secondary pathogens, given that the new mycin-based antibiotics cured nearly 90 percent of cases. However, a review in the British Journal of Venereal Diseases the following year identified four infective candidates as the cause of NGU-bacteria, viruses (which would have included TRIC agents), pleuropneumonia-like organisms (PPLO), and trichomonads - or that it was non-infective and a primary prostate disorder. They concluded that "infection is the probable cause but has not been proved for the majority of cases." The authors also discussed diagnosis and treatment, typically constructing NGU by exclusion: "(1) Whereas gonorrhoea is promptly cured by penicillin, leaving a negligible number of relapses, the position is different with [NGU,] where treatment is less specific, and relapses are common. ... (2) The diagnosis of gonorrhoea in the male is straightforward, but that of [NGU] depends on negative properties and is thus less easily definable." ${ }^{54}$ Despite the uncertainties and the variety of terms and categories, figures for the reported incidence of NGU continued to be published in annual venereal disease statistics. 
When the disease was first reported in 1951, there were 10,764 cases in men; unsurprisingly, no numbers for women were given. ${ }^{55}$ That year there were 14,975 new cases of gonorrhea in men and 3,089 in women. The gonorrhea figures for women were known to be underestimates for two reasons: clinics tended to test only the contacts of infected men, and the infection was known to be often symptomless in women. Diagnosis of NGU still followed the two negatives: the absence of gonococci and non-responsiveness to penicillin. An investigation into the aetiology, published in 1954, which considered just men, did mention women as "consorts" but admitted defeat in identifying any specific "virus" for NGU. However, immunological tests suggested that links with LGV, psittacosis, and cat-scratch fever merited further attention. ${ }^{56}$ In about three-quarters of cases, NGU responded to treatment with antibiotics such as chloramphenicol, aureomycin, terramycin, and erythromycin. ${ }^{57}$ The reported incidence of new cases of NGU in men rose steadily through the 1950 s, such that in 1961 there were 24,472 new cases, against 29,519 of gonorrhea. ${ }^{58}$

In a lecture on "Venereal Disease and Public Health" in 1960, McElligott, who had risen to be adviser in venereal diseases to the Ministry of Health, reflected on the new epidemiological picture of venereal diseases: "Today gonorrhoea and, indeed, early syphilis, promptly and properly treated . . . still have a cure rate of not much less than $100 \%$. Our therapeutic problems now for the most part comprise relapsing NGU in men with its occasional complications, and trichomoniasis in women patients, the latter condition being increasingly sent on to us by our gynaecological colleagues." ${ }^{59}$

He worried too about social attitudes to NGU because, "not being a statutory venereal disease," it had been "neglected by the public and the medical profession alike, and is often regarded as a respectable complaint rather than a dirty disease with disgraceful implications." 60 The incidence of new cases of NGU exceeded those for gonorrhea for the first time in 1965, and this spurred greater interest into the condition among venereologists. Ideas on causation were fixed firmly on microorganisms.

In the 1964 edition of their textbook on venereal diseases, Ambrose King and Claude Nicol noted several possibilities: TRIC agents; mycoplasma, or bacteria without cell walls, like those that caused pleuropneumonia (termed pleuropneumonia-like organisms or PPLOs); Trichomonas vaginalis; fungi; and a Haemophilus influenza organism. ${ }^{61}$ The idea that NGU was an allergic reaction of some type was also mentioned. However, the predominant view was that it was an infection, and the possibility of a link between trachoma and NGU was behind work undertaken by Eric Dunlop, with the Oculogenital Virus group at the Institute of Ophthalmology at Moorfields 
Eye Hospital. ${ }^{62}$ Nonetheless, the nature of the microorganism remained uncertain, as was only too clear in an article on NGU in the Lancet in 1965, in which the authors stated they had been studying "a member of the Bedsonia or psittacosis/lymphogranuloma/TRIC group." 63 Bedsonia is now often regarded as an obsolete term for the Chlamydia group of microorganisms. ${ }^{64}$ The review concluded with suggestions of new names for NGUs in men and, seemingly for the first time, in women: "TRIC agent urethritis" and "TRIC agent cervicitis." 55

It was not until 1971 that the number of new cases of NGU in women was reported in the annual reports of the chief medical officer in Britain. It had been previously discussed in clinical publications but had not been officially recorded because it was "not a clear-cut clinical entity." ${ }^{\prime 6}$ However, cases had been included in "other conditions" requiring treatment within the [VD] center, in which now remained LGV, trichomoniasis, candidiasis, scabies, pubic lice, genital herpes, genital warts, genital molluscum and other treponomal diseases. ${ }^{67}$ The exclusion of chlamydia from the list of "other sexually transmitted diseases" indicated that doctors had decided that it belonged with NGU.

The figures for 1971 were 14,418 new NGU cases in women compared to 62,498 in men, with population rates of 56.54 per 100,000 in women and 263.55 in men. The report observed,

Research on the causative agent or agents in this group continues to be supported by the DHSS and MRC. It is encouraging that at least four centres are now investigating the role of Chlamydia group A organisms in this condition. However, it is still reasonable to suspect that other infective agents are implicated and the possibility that there may be pathogenic strains of mycoplasma cannot be discarded; their isolation in the upper genital tract in women with pelvic complications has been reported from Sweden. The diagnosis of infection in female sex contacts remains a difficult problem, but their diagnosis and treatment seems indicated when there is evidence of inflammatory changes in the genito-urinary tract. ${ }^{68}$

There was discussion of the "epidemiological" or "blind" treatment of "consorts"- that is, giving antibiotics to asymptomatic women contacts of male sufferers with the aim of preventing the reinfection of men and, secondarily, treating women. This indicated that women were still seen as vectors rather than sufferers of NGU. The women's health movement of the 1960s was dependent on established, mostly male, STD specialists and initially focused on the "venereal diseases" of syphilis and gonorrhea. ${ }^{69}$ However, this changed in the 1970s; for example, the 1973 edition of Our 
Bodies, Ourselves included information on "other non-categorized sexually transmitted diseases," but it was not until the 1980s that discussion of the triad of chlamydia, PID, and infertility was added. ${ }^{70}$

\section{Chlamydia: In Fashion Again?}

In 1974 a review article in the Lancet on chlamydia began with the statement: "The Chlamydia genus is in fashion again." 71 The previous occasion alluded to was work on trachoma, but the new attention was because of evidence of its role in genital infection and PID. The article was prompted by the investigations that were finding a "considerable proportion [up to 45 percent] of 'non-specific' genital infection is due to Chlamydia." 72 There was similar evidence from the United States, where a study of 113 men with NGU showed 42 tested positive for $C$. trachomatis and commented that "the cause of chlamydia-negative NGU . . . remains obscure."73 The reference to "'non-specific" genital infection" reflected a shift in terminology as NGU was replaced by NSGI or the more common NSU, which I use from now on. In Britain the key researcher was Eric Dunlop, who is now remembered as "the person who first put chlamydial genital infection in the medical and general public domain"; this was work published in $1972 .{ }^{74} \mathrm{He}$ was an ophthalmologist, and his suggestion that $C$. trachomatis was a cause of pelvic inflammatory disease came from observations of the number of mothers, whose babies had chlamydial ophthalmia neonatorum, suffered from salpingitis. ${ }^{75}$

In the 1975 edition of their textbook, King and Nicol still listed seven possible causal agents of NSU but were confident that "Chlamydia-subgroup $\mathrm{A}$ is, at any rate, one cause of non-specific urethritis." ${ }^{\text {" } 6}$ In the same year a study based on patients at Guy's Hospital in London concluded that only 20 percent were "truly non-specific"; the remainder broke down as follows: chlamydia, 40 percent; mycoplasma, 20 percent; trichomoniasis, 15 percent; and candidiasis, 5 percent. ${ }^{77}$ The diversity of diseases making up NSU remained a challenge and, according to Robbie Morton, a venereologist based in Sheffield, "In spite of much laboratory and other research, nonspecific genital infection continues to be the venereologist's most perplexing problem, clinically, diagnostically and therapeutically." ${ }^{78}$ In 1978, Michael Adler, then at the Middlesex Hospital and following a review of the diagnosis and reporting of NSU, wrote, "It is extremely unsatisfactory that when the disease is discussed, described, diagnosed, and notified no accepted criteria are in existence" and "The commonest diagnosis made in STD clinics [is] the one with the least uniformity." 79 The difficulties in diagnosis were acknowledged in the 
reports of the chief medical officer, where it was noted that "in the absence of specific diagnostic tests outside the research field, therapy remains empirical and the possibilities of control are therefore less than in other sexually transmitted diseases." 80

The tests in the "research field" first used cultures grown in hen's eggs and then less cumbersome techniques with McCoy cells. ${ }^{81}$ Laboratory diagnostic tests began by measuring anti-Chlamydial antibodies using serological methods. ${ }^{82}$ At this time there were well established and relatively inexpensive tests for the main STDs: serology with the Wassermann reaction for syphilis and culturing and microscopy for gonorrhea. Chlamydiae, like viruses, live inside cells not in the intracellular matrix; hence, their manipulation in the laboratory required the same techniques and materials as those for viruses. Relative to the new methods, cell culturing was technically demanding, time consuming, expensive, and difficult to standardize. It was beyond the capacity of most public health and clinical microbiology laboratories. Adler's survey of diagnostic methods being used in the late 1970 s revealed that most clinicians were using microscopy to examine urethral exudates, which were stained and then examined for polynucleated leukocytes-a nonspecific test where the presence of this type of white blood cell is taken as an indicator of an infection. ${ }^{83}$ Such deficiencies led to calls for the development of better testing and the creation of a cell culture service to enable accurate diagnosis of the most common STD. ${ }^{84}$ In Britain the new diagnostic techniques and new interest in chlamydia led to studies of women attending STD clinics and an association with promiscuity. ${ }^{85}$ A study in Manchester, published in 1977, used the new methods and found Chlamydia organisms in 26 percent of the "promiscuous women" attending the Special Clinic and 1 percent among the control "non-promiscuous group"; the latter was in fact "two hundred female members of hospital staff." The authors were still cautious about the status of chlamydia as a cause of STDs but worried that "in this investigation, Chlamydia were isolated from $20 \%$ of asymptomatic females, indicating the possibility of a considerable potential reservoir of infection." 86 Why was this concerning? Principally, concerns were growing about the link between STDs and infertility, as seen in an editorial in the British Medical Journal in 1975, titled "Promiscuity and Infertility," which focused on tubal inflammation caused by gonorrhea. ${ }^{87}$

Two wider changes in STDs in the late 1970s and early 1980s impacted the emergence of chlamydia as an important public health problem: HIV/ AIDS and the medicalization of infertility. I will not go into these in any detail, as there is a large, now historical, literature on each, though, interestingly, chlamydia is rarely mentioned, if at all. ${ }^{88}$ First and most important 
was HIV/AIDS, which radically altered the profile of STDs in medicine and wider society, and the "safe sex" message led to a reported decline in new cases of chlamydia infection in women. ${ }^{89}$ One consequence was that STD services expanded and were better funded, with greater investment in diagnostic services and expertise in viral diseases. Closely related, there was the creation of the new specialism of genitourinary medicine. ${ }^{90}$ GUM clinics replaced the still stigmatized venereal diseases or STD departments and tried to normalize STDs by dealing with them alongside other diseases of the reproductive and excretory systems. Second, there was the medicalization of infertility and the development of in vitro fertilization. ${ }^{91}$ Among many new approaches, doctors sought ways to correct or circumvent blocked fallopian tubes, which in turn drew attention to the possibilities of prevention, through the early recognition of the factors causing salpingitis and other infections of cervix, uterus, and abdomen.

\section{Infection and Infertility}

In the late 1970s medical attention on infection and infertility was focused on intrauterine contraceptive devices as major causes of ectopic pregnancies, salpingitis, and PID. ${ }^{92}$ Pelvic inflammation in women had been recognized since the late nineteenth century, but PID as a clinical entity was constructed in the 1960s, first in relation to septic infection and then to STDs. These links were central to the controversy over the Dalkon Shield, an intrauterine contraceptive device associated with a high incidence of internal injuries and infections in its users and perhaps infertility. ${ }^{93}$ The leading work on the link between infection and infertility focused on salpingitis_-inflammation and obstruction of the fallopian tubes. The leading researchers were in departments of obstetrics and gynecology, such as Lars Weström at the University Hospital in Lund, Sweden, and with the WHO Collaborating Centre for Reference and Research on Trachoma and Other Chlamydial Infections. As early as 1975, they reported a study of 415 women followed over nine and half years: "Tubal occlusion was diagnosed after one infection in 12.8 per cent, after two infections in 35.5 per cent, and after three or more infections in 75 per cent of the women. Tubal occlusion was more common after nongonorrheal than after gonorrhoeal salpingitis." ${ }^{\prime 4}$ In 1980 Weström reported on the long-term effects of PID and recent changes: "The prevalence of women in the post-PID state has increased by a factor of about 1.5 since 1960. Women in the post-PID state have a tenfold increased risk for ectopic pregnancy and $25 \%$ of the increase in ectopic pregnancy can be accounted 
for by the increase in post-PID women." The overall picture was alarming: "Infertility after PID ranges between 5.8\% and 60\% depending on severity of infection, number of infections, and age of the woman. The fraction of women rendered infertile because of PID has increased by a factor of about 1.6 since 1960." 95

An indication of the new medical importance being given to PID was a meeting in April 1980 of an International Symposium at the Centers for Disease Control in Atlanta solely on the condition. ${ }^{96}$ James Curran of CDC explained the problem:

Pelvic inflammatory disease is the most common serious complication of sexually transmitted infections caused by Neisseria gonorrhoeae and Chlamydia trachomatis. If PID and ectopic pregnancy rates continue unabated, by the year 2000 there will have been more than one episode of PID and three related physician visits for every two women who reached reproductive age in 1970. Fifteen per cent will require hospitalization, more than $3 \%$ will experience an ectopic pregnancy, and more than $10 \%$ will involuntarily become sterile because of PID. ${ }^{97}$

Michael Adler, E. H. Belsey, and B. H. O'Connor, from a more limited study than Weström, drew less alarmist conclusions. They focused on gonorrhea and the overall morbidity rather than infertility. However, they noted that the incidence of PID in England and Wales had risen "only" 50 percent between 1968 and 1977, and this would have impacted fertility. ${ }^{98}$ A direct linkage between chlamydia, PID, and infertility was first aired by Duncan Catterall in an article in the Lancet in February 1981 titled "Biological Effects of Sexual Freedom":

The radical changes in attitudes to sex and in sexual behaviour during the past 25 years have resulted in a sustained increase in the incidence of STD. Research has led to the recognition of a new generation of STDs many of which cause pelvic inflammatory disease and sterility. Inability to become pregnant usually, leads to frustration and unhappiness, and treatment is often unsuccessful. The new generation of STDs has serious and potentially dangerous effects on expectant mothers and their babies. Damage to the developing tissues can occur in the uterus, infection may be transmitted at birth, or the infant may develop disease during the first few months of life. Their effects on prematurity, birth weight, early rupture of the membranes, and failure to thrive are only just being investigated, and there may be some surprises. The adverse biological effects of sexual freedom on women and their babies are a disappointing development in the second half of the 20th century. ${ }^{99}$ 
Catterall expected that chlamydia, rather than gonorrhea, as previously thought, was the major cause of PID and ectopic pregnancies. ${ }^{100}$ He worried further that the true level of the chlamydia infection and that of other "new" pathogens was unknown, because, "unfortunately, laboratory facilities are totally inadequate and thousands of cases are unrecognised." ${ }^{101}$ However, he was concerned there was a major problem of fertility decline in the making.

In their large volume on Disease and Fertility (1984), Joseph McFalls and Marguerite McFalls, had separate chapters for NGU and "genital chlamydia" and for the latter detailed experimental and clinical evidence of salpingitis due to chlamydia-impairing conception. ${ }^{102} \mathrm{~A}$ research study published in 1984, using the new method of measuring antibodies rather than cell culture, also found strong indications of $C$. trachomatis infection in 75 percent of women with damaged fallopian tubes, compared with 31 percent of seventy-five infertile women with normal fallopian tubes. ${ }^{103}$ High-antibody levels were found in 15 percent of fertile women. The authors concluded that tests for the microorganism "should routinely be part of infertility investigations." 104 There was support from the new GUM specialists about the scale of the problem, evidenced by the increasing number of ectopic pregnancies, and for wider testing. ${ }^{105}$ In the same year a review in the Journal of Obstetrics and Gynaecology on "Chlamydia trachomatis infections and their importance to the gynaecologist" ended by warning of the "tragic sequelae," citing projections from the United States:

By the year 2000, two out of every three women who had reached reproductive age in 1970 will have had one bout of pelvic inflammatory disease and as a result visited their doctors or sexually transmitted disease clinics three times. Fifteen per cent of this group will have been hospitalised for treatment of pelvic inflammatory disease and of these, one-half will require surgery. Curran (1980) estimates that if one episode of pelvic inflammatory disease confers a 20 per cent chance of infertility then 10 per cent of women in this reproductive age group will have been sterilised by pelvic inflammatory disease alone. ${ }^{106}$

Such apocalyptic warnings diminished through the 1980s, and it is not clear why. One likely factor is that the interests and work of GUM specialists and researchers shifted to HIV/AIDS, where an even greater public health crisis was foreseen. ${ }^{107}$ Also, the improved success rate and availability of in vitro fertilization meant that tubal damage or obstruction was no longer an untreatable cause of infertility. Nonetheless, investigations of the incidence of chlamydia infection continued to be made. A study published in 1991 tested swabs from a cervical cancer-screening clinic in Glasgow and found 6-12 
percent positive, while a study of all women referred in Lothian by general practitioners to GUM clinics found the microorganism in 3.5 percent of samples tested. ${ }^{108}$ In both reports the authors claimed that the incidence was high; though they acknowledged that the number of these infections that led to PID and infertility remained unknown, the implication was that clinical experience pointed to a connection.

\section{Chlamydia: The More You Look the More You Find}

In principle there are two methods of diagnosing an infection: either to isolate and identify the actual pathogen by microscopy or culture methods, or to find a proxy indicator of its presence. In the latter case this might be either a marker from the microorganism (a toxin, membrane protein, or genetic material) termed an antigen or a marker from the immune response of the person infected, typically an antibody. The constructed character of such methods was explored in Ludwig Fleck's classic study of syphilis. ${ }^{109}$ The difficulties in microscopical identification of its bacterial cause-the Trepanoma pallida-led doctors to explore methods that tested the blood serum of the patient for antigens and antibodies. Fleck showed how the accepted method, the Wassermann reaction, was changed from "measuring" antigens to antibodies and, though standardized, produced results that varied between laboratories, influenced by materials, skills, and the meanings attached to results. For example, it was a matter of judgment whether the degree to which a run of tests gave few false positives (a result that indicates that a given condition is present when it is not) or false negatives (a result that indicates that a given condition is absent when it is present). Nonetheless, Fleck showed that the Wassermann reaction, a laboratory test, became as, if not more, important than clinical signs and symptoms in making the diagnosis of syphilis a "fact." The importance of the Wassermann reaction to venereologists meant that they were early adopters, compared to other specialisms, in relying on the laboratory. This was nowhere clearer than with the construction of NGU in the 1930s as the absence of the gonococcus, which was possible because of the routinization of bacteriological investigations in venereal disease clinics, and this has also been the case with chlamydia.

Three ways of diagnosing chlamydia infection were developed: utilizing cell culture, identifying antigens in blood and urine samples, and identifying antibodies in blood. The earliest, cell culturing, was the "gold standard" because the actual organism was "seen," though this required making it visible by staining and fixing, procedures that were demanding, lengthy, and 
expensive. And, as clinicians had effective antibiotics at hand, their practice was to treat first and then, maybe or maybe not, confirm the diagnosis. Cell culturing was highly specific, but there were questions about its sensitivity and accuracy. Specificity, sensitivity, and reliability are key terms in bacteriological testing. Specificity refers to the degree to which a test identifies only a particular microorganism and not other members of the genus or related bacteria. Sensitivity refers to the probability of actually detecting the specific organism, though how this is judged depends on the assumed gold standard for 100 percent detection. Accuracy relates to sensitivity, in relation to the overall percentage of false positives and false negatives but also to the precision and replicability of the test, not least its independence from the equipment and skill levels of technicians in different laboratories and at different times.

Culture methods were improved in the 1970s, first, with the use of irradiated McCoy cells allowing culturing to be standardized. Second, identification was improved when traditional chemical stains were replaced by fluorescently labeled antibodies that adhered to the bacillus, allowing rapid and specific identification through a microscope with ultraviolet light. ${ }^{110}$ This method, developed first for trachoma and LGV, was nearly 100 percent specific, though its laboratory sensitivity was estimated at only 70-85 percent and overall sensitivity lower, at $40-85$ percent, due to sampling errors and variable laboratory standards. ${ }^{111}$ There remained the question of the quality of the samples tested: might microorganisms have been missed in taking swabs, urine, and blood samples or died between clinic and laboratory?

In the 1980s there was a return to vogue of microscopical identification without culturing, using a technique known as direct fluorescence assay. The test involved attaching specially manufactured antibodies to specific sites on the outer membrane of Chlamydia. Specimens taken from the urethra and reproductive organs were allowed to react with antibodies, which also carried luminescence-labeled reagents. After washing, the sample was examined for any antibodies remaining adhered to microorganisms, with clinical pathologists looking for bright spots, typically green, under ultraviolet light. When compared with other methods results were more variable, influenced by many factors, including the recognition that were three strains or serotypes of $C$. trachomatis. Nonetheless, it was used because it was quick and relatively inexpensive.

Advances in molecular biology, many developed by the new biotechnology companies and using monoclonal antibodies, revolutionized the laboratory diagnosis of all diseases, and chlamydia was no exception. ${ }^{112}$ There were new tests for antibodies (complement fixation and a 
microimmunofluorescence) and new antigen tests (direct fluorescence assay and enzyme immunoassay). ${ }^{113}$ There was intense competition between the companies producing the tests, as the demand for diagnostic testing and, later, screening for chlamydia grew. Manufacturers made competing claims for specificity, sensitivity, and accuracy, as well as price and speed. All were compared to the gold standard of cell culture, though there were increasing doubts that this was any better than any of the new tests. ${ }^{114}$ It was a difficult argument to settle, as the different tests were testing for different things; nonetheless, the public health authorities in England and Wales had sufficient confidence to include new cases of chlamydia in the STI statistics from 1990.

In the 1990s new tests became available that used the new DNA technologies, most notably the polymerase chain reaction technologies, to develop nucleic acid amplification tests (NAATs). ${ }^{115}$ In these tests fragments of Chlamydia DNA extracted from clinical samples were duplicated in repeating cycles, to produce samples large enough for colorimetric evaluations. The first such test was introduced by Roche in 1993-Amplicor C. trachomatis. The following year an evaluation made by doctors in Bordeaux found that it had a sensitivity of 95.3 percent and a specificity of 100 percent and concluded that it was superior to culture methods. ${ }^{116}$ Other tests from other companies followed: the ligase chain reaction from Abbott Laboratories Illinois and transcription mediated amplification from GenProbe, La Jolla, California. A review of the new tests found that while they were based on different molecular strategies, they had equivalent specificity and sensitivity to Roche Amplicor. ${ }^{117}$ In a review in 1998 interestingly titled "Chlamydia trachomatis: The More You Look the More You Find; How Much Is There?," Julius Schachter suggested it was time to abandon the old assumptions:

There has been a revolution in diagnostic methodology in recent years with the introduction of nucleic acid amplification tests (NAAT). These tests are far more sensitive than any of the earlier nonculture tests. For the first time, diagnostic laboratories have a technology that is more sensitive than isolation in tissue culture (TC). TC, which has long been considered the gold standard for diagnosis of C. trachomatis, is recognized as having a specificity approaching $100 \%$ but is considered to be less sensitive, with estimates typically being on the order of $75 \%$ to $85 \%$ sensitivity in expert laboratories. The NAAT have shown that these estimates of the sensitivity of cell culture are overestimates. There is even a wider variability in the performance of culture from laboratory to laboratory, than had been previously surmised. 
The new methods had, he argued, completely changed the landscape.

The nonculture methods led to broad-based testing for C. trachomatis and changed chlamydia diagnostics from being a cottage industry into being on the regular public health laboratory menu. But these tests were even less sensitive than culture. The NAAT offered tests that were more sensitive than culture. We became aware that the estimates of prevalence of infection determined in the past by either TC [tissue culture] or early nonculture tests (antigen detection methods or the direct nucleic acid probes) were gross underestimates. The number of infections detected by nucleic acid amplification tests could be higher by up to $80 \%$ as compared with the use of the older technology. ${ }^{118}$

The improvement offered by the new DNA-based techniques were indicated in a study published in 1997, where the older enzyme immunoassay methods found a prevalence of 1.6 percent ( 0.8 to 2.7 percent), with a sensitivity of 60 percent and a specificity of 100 percent, while the ligase chain reaction found 2.5 percent ( 1.5 to 3.9 percent), with 90 percent sensitivity and 99.8 percent specificity. Not only did the new technologies offer greater specificity, sensitivity, and accuracy; they were cheaper and easier. Hence, it became possible to move beyond diagnostic testing to screening for symptomless chlamydia infection in both men and women. Paradoxically, the NAAT technologies may have been responsible for the continuing increase in reported new cases, as they enabled more tests to be made and with greater sensitivity. ${ }^{119}$

The possibility of large-scale screening became policy in Britain in 1998, when the government accepted the recommendation of the chief medical officer's Expert Advisory Group's report on Chlamydia trachomatis that a pilot trial be made. ${ }^{120}$ Two groups were tested systematically: women and men attending GUM clinics and women seeking termination of pregnancy; there was also to be opportunistic screening of sexually active women aged under twenty-five, especially teenagers. Why make the trial? First, there was the rising annual rate of new cases of chlamydia, which reached fifty thousand in 1998-99, over three times that for gonorrhea; and, second, so much infection is asymptomatic, and, untreated, its consequences for women were severe and lifelong and had implications for society at large. An editorial in the British Medical Journal welcomed the report and stressed the importance of its recommendations. "The role of chlamydia in infertility is well documented: the disease may be implicated in as much as $50 \%$ of cases. Many cases of infertility occur in the absence of clinical pelvic inflammatory disease, and when this disease process occurs is unknown. A reduction of the 
incidence of chlamydia infection in the community may therefore produce a corresponding fall in the related incidence of infertility." 121

Pilot studies showed high rates-10 percent infected-among young women attending general practitioners and other clinics. ${ }^{122}$ This prompted the establishment in September 2002 of the National Chlamydia Screening Programme, by which time new chlamydia cases each year was approaching a hundred thousand. The program "offered" screening to all women and men under twenty-five years of age attending various clinical setting using NAATs. The technical term for this type of screening was "opportunistic" - that is, it was offered, but it was up to patients whether to accept and to practitioners how strongly, if at all, they encouraged participation. Nonetheless, in the first year over 16,000 samples were tested (15,241 women and 1,172 men). Excluding those seen at GUM clinics and assumed to represent the general population of young adults, the program found "chlamydia positivity among people under 25 years of age screened in non-GUM settings was $10.1 \%(1538 / 15,241)$ in women and $13.3 \%(156 / 1172)$ in men." ${ }^{123}$ Views on the program were mixed. Some doctors complained that it was hardly a public health measure as long as screening remained opportunistic. The participation of general practitioners was optional and not incentivized; few men were screened and contacts untraced. ${ }^{124}$ On the other side there were questions about its cost-effectiveness, in part because of new views on the natural history of the infection:

Increasing evidence shows that the rate of progression of endocervical chlamydia to pelvic inflammatory disease is lower than previously thought. Population based studies consistently estimate lower incidence rates of pelvic inflammatory disease than clinic-based studies. Infections detected by screening asymptomatic people might therefore have a better prognosis than symptomatic infections, because of differences in the burden of the organism. Descriptions of chlamydial infection and its consequences, and models of the impact of screening, however, nearly always cite the higher estimates. ${ }^{125}$

It was, of course, unsurprising that those who were promoting screening used the data that supported their case, but equally interesting was the redefinition of the problem to be tackling pelvic inflammatory disease rather than infertility. This change may have been due to the impact of gender politics, considering women's health as such, rather than in terms of motherhood, and the impact of in vitro fertilization, but it also reflected less confidence in the extent to which chlamydia is a direct and major cause of infertility. This is borne out by later assessments. A Cochrane Review published in 2013 
found the following: "In women, chlamydia ascends to the upper genital tract in approximately $10 \%$ of cases to cause symptomatic pelvic inflammatory disease (PID). The resulting tubal damage can then cause ectopic pregnancy, tubal infertility and chronic pelvic pain. Although about $45 \%$ of tubal infertility might be attributable to chlamydia infection, the probability of tubal infertility in women who have had chlamydia is estimated to be only $1 \%$ to $4 \% . " 126$

The range of these population estimates is very wide, and such uncertainties mean that how, and to what extent, $C$. trachomatis infection causes infertility has remained a subject of intense research. A 2015 study of the subject concluded, after discussing the complex interactions of host, immunological, epidemiological, and pathogen factors, that "the actual process of host and pathogen factors that result in infertility remain uncertain and require further investigation." 127

\section{From Male NGU to Female Chlamydia}

Chlamydia as an STI was constructed medically and socially from the breakup of NGU as a clinical entity in the 1970s. There was no eureka moment. Rather, there was a slow buildup of evidence, from laboratory investigations using the new tools of molecular biology, that NGU-which had become an embarrassment to STI specialists as a catch-all, negative diagnosis-was a number of distinct infections. Given that my approach followed Rosenberg's maxim that "a disease does not exist until we have agreed that it does, by perceiving, naming, and responding to it," it might be thought inconsistent that I begin with discussion of the construction of NGU in the 1930s. Does this mean my history is presentist and teleological in assuming that chlamydia was always present in NGU? In part, yes: all history is a dialogue between the present and the past, and we cannot escape our knowledge of the deconstruction of NGU in component parts from the 1970s. But also, no: I discuss the emergence of NGU in its historical context as a disease entity in its own right, not as a mistaken, temporary entity whose demise was inevitable. NGU was modeled as having symptoms like gonorrhea, but also unlike it in not being caused by the gonococcus. However, there was another largely unremarked difference. Venereologists found no place for female disease in the new infection, which leads to questioning how well integrated into their practice was concern about the extent and seriousness of gonorrhea in women shown by gynecologists and pathologists, and championed by the suffragettes, in the early twentieth century. The maleness 
of NGU was further enshrined by the work of venereal disease services in World War II and medical and social attitudes that saw women as only consorts and contacts.

NGU attracted increased attention in the 1970s from STD specialists and researchers because of its increased incidence and continuing dissatisfaction with its uncertain causes. The application of cell culture techniques made possible the isolation of $C$. trachomatis from patients with GNU. This new modeling of the disease made it similar in aetiology and pathology to gonorrhea, which led clinicians to ask about the consequences of the infection in women more generally. The link between chlamydia and PID was well established by the early 1980s, specifically to salpingitis and ectopic pregnancies. This coincided with new medical interventions and social concern about infertility, which led to the reconstruction of chlamydia as a female disease, as seen in the development of screening programs targeted at women. This was not in terms of incidence-it was assumed to be equal in both sexesbut, because it was symptomatic in men, it was treatable, whereas in women symptomless, untreated infection was linked to infertility and PID. The main prompt for this reconstruction was the rising incidence of new cases of chlamydia in young women and projections of the long-term effects of untreated or repeat infection over childbearing years. The association between chlamydia, infertility, and PID proved to be powerful in mobilizing public health initiatives. However, these programs have come under scrutiny for their cost-effectiveness-future benefits in fertility and cost savings remain projections and easy targets for cuts. Furthermore, while no one doubts that chlamydia is a factor in infection-induced infertility, there continue to be ambivalent findings on how, and to what extent, $C$. trachomatis infection is a direct cause of infertility.

\section{Notes}

The research for this chapter was funded by a Wellcome Trust Programme Grant (WT 092782). The initial work for this chapter was undertaken collaboratively with John Craske, whose expert advice on microbiology was invaluable. And, finally, thanks goes to the many colleagues and students with whom I have discussed the work, but especially Ian Burney, Ian Clarke, Simon Szreter, Carsten Timmermann, and Elizabeth Toon.

1. Over the period discussed in this chapter, the terms for different diseases and groups of diseases changed. I employ mostly the terms used by historical actors in their context but sometimes have altered them to aid the clarity of the narrative. Sexually transmitted infection (STI) has been preferred since the 1990s to sexually 
transmitted disease (STD), which in turn replaced venereal disease or diseases (VD) in the 1970s.

2. Michael Worboys, Spreading Germs: Disease Theories and Medical Practice in Britain, 1865-1900 (Cambridge: Cambridge University Press, 2000).

3. Public Health England, "Sexually Transmitted Infections and Screening for Chlamydia in England, 2017," Health Protection Report 12, no. 20 (2018), https://assets.publishing.service.gov.uk/government/uploads/system/uploads/ attachment_data/file/713944/hpr2018_AA-STIs_v5.pdf.

4. W. J. Hellstrom et al., "Is There a Role for Chlamydia Trachomatis and Genital Mycoplasma in Male Infertility?," Fertility and Sterility 48 (1987): 337-39; M. K. Samplaski et al., "Review Article: Chlamydial Infection and Its Role in Male Infertility," Advances in Andrology 2014 (2014): 1-11.

5. Beezy Marsh, "The Girls Facing a Fertility Timebomb," Daily Mail, December 12, 2002; M. Thrift, "Britain's Fertility Timebomb," Independent, June 20, 2005.

6. C. H. Mercer et al., "Changes in Sexual Attitudes and Lifestyles in Britain through the Life Course and over Time: Findings from the National Surveys of Sexual Attitudes and Lifestyles (Natsal)," Lancet 382 (2013): 1781-94.

7. L. O. Guerra et al., "Pathogenesis of Chlamydia trachomatis in Humans," in Human Emerging and Re-emerging Infections: Bacterial and Mycotic Infections, ed. S. K. Singh, 635-48 (Hoboken: Wiley, 2006).

8. See Ian N. Clarke and Hugh R. Taylor, chap. 4, in this volume.

9. N. S. Galbraith et al., "Changing Patterns of Communicable Disease in England and Wales, Part III: Increasing Infectious Diseases," British Medical Journal 281 (1980): 5464-69.

10. Hugh R. Taylor, Trachoma: A Blinding Scourge from the Bronze Age to the Twenty-First Century (Melbourne: Centre for Eye Research, 2008); see also Clarke and Taylor, chap. 4, in this volume; and J. Schachter, "Chlamydia psittaci: 'Re-Emergence' of a Forgotten Pathogen," New England Journal of Medicine 315 (1986): 189-91.

11. S. K. West and P. Courtright, “Trachoma Control: 14 Years Later," Ophthalmic Epidemiology 22 (2015): 145-47.

12. D. Taylor-Robinson, "The History of Nongonococcal Urethritis: Thomas Parran Award Lecture," Sexually Transmitted Diseases 23 (1996): 86-91; J. D. Oriel, "The History of Non-gonococcal Urethritis," Genitourinary Medicine 72 (1996): 374-79.

13. Charles E. Rosenberg, "Framing Disease: Illness, Society and History," in Framing Disease: Studies in Cultural History, ed. C. E. Rosenberg and J. Golden (New Brunswick: Rutgers University Press, 1992), xv.

14. Peter Sedgwick, Psychopolitics (London: Pluto, 1982), 30-31.

15. Rosenberg, "Framing Disease."

16. R. C. Burnham, "Immunity to Chlamydia trachomatis," Journal of Infectious Diseases 207 (2013): 1796-97.

17. See Roy F. Scragg, chap. 7, in this volume. 
18. Michael Worboys, "Unsexing Gonorrhoea: Bacteriologists, Gynaecologists, and Suffragists in Britain, 1860-1920," Social History of Medicine 17 (2004): 41-59; Elliott Bowen, "Limits of the Lab: Diagnosing 'Latent Gonorrhea,' 1872-1910," Bulletin of the History of Medicine 87 (2013): 63-85.

19. L. V. Weström, "Chlamydia and Its Effect on Reproduction," Journal of the British Fertility Society 1 (1996): 23-30.

20. Anne Hanley, “'Scientific Truth into Homely Language': The Training and Practice of Midwives in Ophthalmia Neonatorum, 1895-1914." Social History of Medicine 27 (2014): 199-220.

21. There were calls for the infection to be made notifiable, which it was in certain towns, to ensure medical practitioners were called on to treat babies if midwives had not done so. S. Stephenson, Ophthalmia Neonatorum, with Especial Reference to Its Causation and Prevention (London: Pulman and Sons, 1907); T. G. Benedek, "Gonorrhea and the Beginnings of Clinical Research Ethics," Perspectives in Biology and Medicine 48 (2005): 54-73.

22. Christabel Pankhurst, The Great Scourge and How to End It (London: Pankhurst 1913); Emmeline S. Pankhurst, The Suffragette Movement (London: Longmans, 1932), 521.

23. C. Pankhurst, Great Scourge, 83-84.

24. Aleck B. Bourne, "Discussion of the Treatment of Salpingitis," British Medical Journal 2 (1923): 399-400.

25. Anne Hanley, “'The Great Foe to the Reproduction of the Race': Diagnosing and Treating Infertility Caused by Venereal Disease, 1880-1914," in Infertility in History: Approaches, Contexts and Perspectives, ed. Gayle Davis and Tracy Loughran, 335-58 (London: Palgrave Macmillan, 2016).

26. Simon Szreter, "The Prevalence of Syphilis in England and Wales on the Eve of the Great War: Re-visiting the Estimates of the Royal Commission on Venereal Diseases, 1913-1916," Social History of Medicine 27 (2014): 527-29.

27. R. A. Gibbons, "Sterility: Its Etiology and Treatment," Lancet 176 (1910): 708. See also Christina Benninghaus, chap. 10; and Fabrice Cahen and Adrien Minard, chap. 11, both in this volume.

28. C. C. Norris, Gonorrhea in Women: Its Pathology, Symptomatology, Diagnosis, and Treatment; Together with a Review of the Rare Varieties of the Disease Which Occur in Men, Women and Children (Philadelphia: Saunders, 1913), 127.

29. "Antenatal Treatment of Gonorrhoea," Lancet 211 (1928): 757-58.

30. "Gonorrhoea, Epididymitis and Sterility," Lancet 201 (1923): 1017; J. W. Burns, "Chronic Endocervicitis and Its Treatment," Lancet 200 (1922): 796-99; Report on the British Congress of Obstetrics and Gynaecology, "Puerperal Sepsis," Lancet 205 (1925): 919-21; M. Huhner, "The Role of the Gonococcus in Sterility," American Journal of Surgery 4 (1928): 299-303.

31. Maeve Kenny, "Remote Effects of Puerperal Sepsis," Lancet 229 (1937): $14-16$. 
32. Leonard Colebrook, "The Story of Puerperal Fever: 1800-1959," British Medical Journal 1 (1956): 247-52; Irvine Loudon, "Puerperal Fever, the Streptococcus, and the Sulphonamides, 1911-1945," British Medical Journal 295 (1987): 485-90.

33. "Chemotherapy of Gonorrhoea," editorial, British Medical Journal 2 (1938): 665-66; "The Chemotherapy of Gonorrhoea," editorial, Lancet 232 (1938): 381.

34. A. J. Cokkinis, "The Treatment of Gonorrhoea with Oral Sulphanilamide," British Medical Journal 2 (1937): 905-9.

35. A. Malcolm Simpson, "Over-Treatment of Gonorrhoea," Lancet 229 (1937): 899.

36. A. J. Cokkinis, "Sulphonamide in Genito-Urinary (Non-gonococcal) Infections," British Medical Journal 2 (1938): 1151-55.

37. "Obituary Notices: A. H. Harkness, F.R.C.S.," British Medical Journal 4 (1970): 562; “Obituary: Arthur Herbert Harkness, F.R.C.S.," Lancet 296 (1970): 1145 .

38. J. D. Oriel, The Scars of Venus: A History of Venereology (London: Springer, 1994), 161-65.

39. A. H. Harkness, "Non-gonococcal Urethritis," British Journal of Venereal Disease 9 (1933): 173-86, 187-91.

40. Lawrence W. Harrison and Werner Worms, "The Relation between Some Forms of Non-gonococcal Urethritis, Lymphogranuloma Inguinale, Trachoma, and Inclusion Blennorrhœa: Critical Review," British Journal of Venereal Disease 15 (1939): 237-59.

41. R. E. Wright, "The Trachoma Problem," British Journal of Ophthalmology 19 (1935): 309-18. See also Clarke and Taylor, chap. 4, in this volume; and Taylor, Trachoma, 19.

42. S. S. Meighan, "Trachoma in Glasgow," British Journal of Ophthalmology 19 (1935): 326.

43. E. de Grósz, "Campaign against Trachoma," British Journal of Ophthalmology 19, no. 6 (1935): 320.

44. S. S. Hughes, The Virus: A History of the Concept (London: Heinemann, 1977); Victoria A. Harden, Rocky Mountain Spotted Fever: History of a TwentiethCentury Disease (Baltimore: Johns Hopkins University Press, 1990).

45. A. W. Downie, "Bedson, Sir Samuel Phillips (1886-1969)," Oxford Dictionary of National Biography, rev. ed. (Oxford: Oxford University Press, 2004), www.oxforddnb.com/view/article/30668.

46. A. E. W. McLachlan, Handbook of Diagnosis and Treatment of Venereal Diseases (Edinburgh: Livingstone, 1944).

47. D. Lees, Practical Methods in the Diagnosis and Treatment of Venereal Diseases, 3rd ed. (Edinburgh: Livingstone, 1937), chap. 13; A. E. W. McLachlan, Handbook of Diagnosis and Treatment of Venereal Diseases, 3rd ed. (Edinburgh: Livingstone, 1947), 232; J. Marshall, The Venereal Diseases (London: Macmillan, 1948), 299-323. 
48. G. L. M. McElligott, "Non-gonococcal Urethritis," British Journal of Venereal Disease 18 (1942): 106-12.

49. I. N. Orpwood-Price, "Non-gonococcal Urethritis," British Journal of Venereal Disease 18 (1942): 106-12; R. R. Willcox, "The Etiology of Nongonococcal (Nonspecific) Urethritis," Journal of Chronic Disease 1 (1956): 381-91.

50. Report of the WHO Expert Committee on Venereal Diseases (Geneva: World Health Organization, 1948). See reports in British Journal of Venereal Disease 25 (1949): 206-7; and Bulletin of the World Health Organization 2 (1949): 139-54.

51. A. H. Harkness, Non-gonococcal Urethritis: Including the Genital Manifestations of Local and Systemic Diseases and Infestations of the Urinary Tract with Protozoa, Metazoa and Fungi, Etc. (Edinburgh: Livingstone, 1950).

52. Ministry of Health, Report of the Ministry of Health Covering the Period from 1st April 1950 to 31st December 1951, pt. 2, On the State of the Public Health, Being the Annual Report of the Chief Medical Officer for the Year 1950, Parliamentary Papers, 1951-52, Cmd. 8582, at 15:315; and pt. 3, On the State of the Public Health, Being the Annual Report of the Chief Medical Officer for the Year 1951, Parliamentary Papers, 1952-53, Cmd. 8787, at 8:302.

53. A. H. Harkness and C. S. Nicol, "Non-gonococcal Urethritis" Public Health 68 (1954): 10-12.

54. A. Grimble and G. W. Csonka, "Skin Testing in 246 Patients with Nonspecific Urethritis with a Review of the Important Literature," British Journal of Venereal Diseases 31 (1955): 228-34.

55. Ministry of Health, Report, pt. 2, On the State of the Public Health, Being the Annual Report of the Chief Medical Officer for the Year 1951, Parliamentary Papers, 1952-53, Cmd. 8787, at 3:302-3.

56. R. R. Willcox, "Researches in Aetiology of Non-specific Urethritis," British Medical Journal 1 (1954): 13-15.

57. R. S. Morton and L. Reed, "Non-gonococcal Urethritis: An Investigation to Determine Factors in the Host Influencing Response to Treatment and Recurrence of Symptoms," British Journal of Venereal Diseases 33 (1957): 223-27.

58. Ministry of Health, Report, pt. 2, On the State of the Public Health, being the Annual Report of the Chief Medical Officer, Parliamentary Papers, 1962-63, Cmnd. 1856, at 19:281.

59. G. L. M. McElligott, "Venereal Disease and Public Health," British Journal of Venereal Diseases 36 (1960): 207-15.

60. McElligott, "Venereal Disease," 214.

61. A. King and C. Nicol, Venereal Diseases (London: Cassell, 1964).

62. B. Goh, “Obituary: Eric Dunlop," Sexually Transmitted Infections 76 (2000): 235.

63. E. Dunlop et al., "Infection of Urethra by TRIC Agent in Men Presenting Because of Non-specific Urethritis," Lancet 285 (1965): 1125-28. 
64. "Chlamydiaceae," National Center for Biotechnology Information, accessed September 30, 2016, http://www.ncbi.nlm.nih.gov/Taxonomy/Browser/wwwtax. cgi? mode $=$ Tree $\&$ id $=809$.

65. E. Dunlop et al., "Infection of Urethra," 1172.

66. "Venereal Diseases in England and Wales: Extract from the Annual Report of the Chief Medical Officer for the Year 1967," British Journal of Venereal Diseases 45 (1969): 67.

67. "Sexually Transmitted Diseases: Extract from the Annual Report of the Chief Medical Officer of the Department of Health and Social Security for the Year 1972," British Journal of Venereal Diseases 50 (1974): 75-77.

68. "Sexually Transmitted Diseases: Extract from the Annual Report of the Chief Medical Officer of the Department of Health and Social Security for the Year 1971," British Journal of Venereal Diseases 49 (1973): 89-95, 93.

69. Boston Women's Health Collective, Women and Their Bodies: A Course (Boston: New England Free Press, 1970), 49-58.

70. K. Davis, The Making of Our Bodies, Ourselves (London: Duke University Press, 2007), 28.

71. "Chlamydia and Genital Infection," editorial, Lancet 304 (1974): 264-65.

72. Eric M. C. Dunlop, "Some Aspects of Sexually Transmitted Diseases Today," Proceedings of the Royal Society of Medicine 68 (1975): 13; Dunlop et al., "Chlamydia and Non-specific Urethritis," British Medical Journal 2 (1972): 575-77.

73. K. King et al., "Etiology of Nongonococcal Urethritis," New England Journal of Medicine 292 (1975): 1199-205.

74. Goh, "Obituary"; Eric M. C. Dunlop et al., "Chlamydial Infection: Incidence in 'Non-specific' Urethritis," British Journal of Venereal Diseases 48, no. 6 (1972): 425-28.

75. Goh, "Obituary."

76. Ambrose King and Claude Nicol, Venereal Disease (London: Baillière Tindall, 1975), 259.

77. A. S. Grimble and K. L. Amarasuriya, "Non-specific Urethritis and the Tetracyclines," British Journal of Venereal Disease 51 (1975): 204.

78. R. S. Morton and J. R. W. Harris, eds., Recent Advances in Sexually Transmitted Diseases (Edinburgh: Churchill Livingstone, 1975), 251.

79. Michael W. Adler, "Diagnostic, Treatment, and Reporting Criteria for Nonspecific Genital Infection in Sexually Transmitted Disease Clinics in England and Wales," British Journal of Venereal Disease 54 (1978): 422-27.

80. "Sexually Transmitted Diseases" (1972), 73.

81. L. N. Pedersen, B. Herrmann, and J. Kjølseth Møller, “Typing Chlamydia trachomatis: From Egg Yolk to Nanotechnology," FEMS Immunology and Medical Microbiology 55 (2009) 120-30.

82. Dunlop et al., "Chlamydia and Non-specific Urethritis"; P. Reeve et al., "Serological Studies on the Role of Chlamydia in the Aetiology of Non-specific Urethritis," British Journal of Venereal Disease 50 (1974): 136-39. 
83. Adler, "Reporting Criteria"; World Health Organization, The Epidemiology of Infertility, WHO Technical Report Series Number 582 (Geneva: World Health Organization, 1975); L. Weström and P. A. Mårdh, "Pelvic Inflammatory Disease: Epidemiology, Diagnosis, Clinical Manifestations and Sequelae," Report of WHO Scientific Group on Non-gonococcal Urethritis and Other Selected Sexually Transmitted Diseases of Public Health Importance (Geneva: World Health Organization, 1978), 347.

84. J. R. Willcox et al., "The Need for a Chlamydial Culture Service," British Journal of Venereal Disease 55 (1979): 281-83; D. Taylor-Robinson and P. E. Munday, "Chlamydia Culture Service," British Journal of Venereal Disease 56 (1980): 183.

85. A. S. Hilton, "Chlamydia A in the Female Genital Tract," British Journal of Venereal Diseases 50 (1974): 1-10.

86. J. M. Woolfitt and L. Watt, "Chlamydial Infection of the Urogenital Tract in Promiscuous and Non-promiscuous Women," British Journal of Venereal Diseases 53 (1977): 93-95.

87. "Promiscuity and Infertility," editorial, British Medical Journal 3 (1975): $501-2$.

88. The literature on HIV/AIDS also makes little mention of other STIs, such as gonorrhea and syphilis. See Virginia Berridge, AIDS in the UK: The Making of Policy, 1981-1994 (Oxford: Oxford University Press, 1996); and Elizabeth Fee and Daniel M. Fox, AIDS: The Making of a Chronic Disease (Berkeley: University of California Press, 1992). There is discussion of infertility due to STIs in Naomi Pfeffer, The Stork and the Syringe: Political History of Reproductive Medicine (Oxford: Polity, 1993), 8-12, 49-50.

89. K. Shanmugaratum and R. S. Pattman, "Declining Incidence of Chlamydia Trachomatis in Women Attending a Provincial Genitourinary Medicine Clinic," Genitourinary Medicine 65 (1989): 400; K. Sivakumar and R. Basu Roy, "Declining Prevalence of Chlamydia Trachomatis in Women Attending a Provincial Genitourinary Medicine Clinic,” Genitourinary Medicine 65 (1989): 400.

90. "Obituary: Duncan Catterall," Independent, July 5, 1993.

91. Gayle Davis and Tracey Loughran, "Introduction: Situating Infertility in Medicine," and Anne Hanley, "The Great Foe to the Reproduction of the Race': Changing Medical Knowledge and Practice; Diagnosing and Treating Infertility Caused by Venereal Diseases, 1880-1914," both in The Palgrave Handbook of Infertility in History: Approaches, Contexts, Perspectives, ed. Gayle Davis and Tracey Loughran (London: Palgrave Macmillan 2017), 265-72, 344-49.

92. "Ectopic Pregnancy and the I.U.D.," editorial, Lancet 306 (1975): 963.

93. L. Weström, L. P. Bengtsson, and P. A. Mårdh, "The Risk of Pelvic Inflammatory Disease in Women Using Intrauterine Contraceptive Devices as Compared to Non-users," Lancet 308 (1976): 221-24; J. R. Daling, "Primary Tubal Infertility in Relation to the Use of an Intrauterine Device," New England Journal of Medicine 312 (1985): 937-41; N. J. Grant, The Selling of Contraception: The Dalkon 
Shield Case, Sexuality, and Women's Autonomy (Columbus: Ohio State University Press, 1992); P. D. Darney, "Time to Pardon the IUD?," New England Journal of Medicine 345 (2001): 608-10.

94. L. Weström, "Effect of Acute Pelvic Inflammatory Disease on Fertility," American Journal of Obstetrics and Gynecology 121 (1975): 707-13.

95. L. Weström, "Incidence, Prevalence, and Trends of Acute Pelvic Inflammatory Disease and Its Consequences in Industrialized Countries," American Journal of Obstetrics and Gynecology 138 (1980): 880-92.

96. "Pelvic Inflammatory Disease, 1980," American Journal of Obstetrics and Gynecology 138 (1980): 845-1112.

97. J. W. Curran, "Economic Consequences of Pelvic Inflammatory Disease in the United States," American Journal of Obstetrics and Gynecology 138 (1980): 848-51.

98. Michael W. Adler, E. H. Belsey, and B. H. O’Connor, "Morbidity Associated with Pelvic Inflammatory Disease," Sexually Transmitted Infections 58 (1982): 15157. See also Michael W. Adler, "Trends for Gonorrhoea and Pelvic Inflammatory Disease in England and Wales and for Gonorrhoea in a Defined Population," American Journal of Obstetrics and Gynecology 138 (1980): 901.

99. R. D. Catterall, "Biological Effects of Sexual Freedom," Lancet 317 (1981): 318-19.

100. M. J. Hare, "Pelvic Inflammatory Disease," British Medical Journal 4 (1986): 1225-28. See also L. Weström, "Chlamydial Salpingitis," British Medical Bulletin 39 (1983): 145-50.

101. Hare, "Pelvic Inflammatory Disease," 1225-28.

102. J. A. McFalls and M. H. McFalls, Disease and Fertility (Orlando: Academic Press 1984), 258-307, 377-85.

103. D. Conway et al., "Chlamydial Serology in Fertile and Infertile Women," Lancet 323 (1984): 191-93. The authors cited similar findings from investigations in the United States and Finland.

104. Conway et al., "Chlamydial Serology," 192.

105. See correspondence on the question: "Is the Incidence of Ectopic Pregnancy Rising?," British Medical Journal (Clinical Educational Research) 291 (1985): 967, 1199-200, 1426.

106. J. L. Lane, "Chlamydia trachomatis Infections and Their Importance to the Gynaecologist," Journal of Obstetrics and Gynaecology 4 (1984): 253. Lane's comment is based on data from Curran, "Economic Consequences."

107. D. Taylor-Robinson, "Chlamydia trachomatis and Sexually Transmitted Disease," British Medical Journal 308 (1994): 150.

108. J. R. Smith, "Prevalence of Chlamydia trachomatis Infection in Women Having Cervical Smear Tests," British Medical Journal 302 (1991): 82-84; J. D. C. Ross et al., "Genital Chlamydia trachomatis Infections in Primary Care," British Medical Journal 313 (1996): 1192. 
109. L. Fleck, Genesis and Development of a Scientific Fact (1935; repr., Chicago: University of Chicago Press, 1979); Ilana Löwy, "Ludwig Fleck and the Social Construction of Medical Knowledge," Sociology of Health and Illness 10 (1988): $133-55$.

110. J. D. Oriel, "Chlamydial Infection: Isolation of Chlamydia from Patients with Non-specific Genital Infection," British Journal of Venereal Diseases 48 (1972): 429-36.

111. J. T. Grayston and S. Wang, "New Knowledge of Chlamydiae and the Diseases They Cause," Journal of Infectious Diseases 132 (1975): 87-105.

112. Lara V. Marks, The Lock and Key of Medicine: Monoclonal Antibodies and the Transformation of Health Care (New Haven: Yale University Press, 2015).

113. For a review of methods from the 1960s to the 1990s, see C. M. Black, "Current Methods of Laboratory Diagnosis of Chlamydia trachomatis Infections," Clinical Microbiology Review 10 (1997): 160-84.

114. T. Crowley et al., "The Laboratory Diagnosis of Male Chlamydia Trachomatis Infections: A Time for Change?," Journal of Infection 25 (1992): 69-75. See also J. W. Newhall et al., "Head-to-Head Evaluation of Five Different Non-culture Chlamydia Tests Relative to a Quality-Assured Culture Standard," Sexually Transmitted Diseases 21 (1994): S165-66; and P. E. Hay et al., "Chlamydia trachomatis in Women: The More You Look, the More You Find," Genitourinary Medicine 70 (1994): 97.

115. Black, "Current Methods," 164-75.

116. B. de Barbeyrac et al., "Evaluation of the Amplicor Chlamydia trachomatis Test Versus Culture in Genital Samples in Various Prevalence Populations," Genitourinary Medicine 70 (1994): 162-66.

117. J. Schachter, "Chlamydia trachomatis: The More You Look the More You Find; How Much Is There?," Sexually Transmitted Diseases 25 (1998): 229-31. See also J. Schachter, "DFA, EIA, PCR, LCR and Other Technologies: What Tests Should Be Used for Diagnosis of Chlamydia Infections?," Immunological Investigations 26 (1997): 157-61.

118. Schachter, "Chlamydia trachomatis, 230.

119. M. J. Rekart and R. C. Burnham, "Epidemiology of Chlamydia: Are We Losing Ground?," Sexually Transmitted Infections 84 (2008): 87-91.

120. Chief Medical Officer's Expert Advisory Group, Main Report of the CMO's Expert Advisory Group on Chlamydia trachomatis (London: Department of Health, 1998), accessed September 29, 2016, http://webarchive.nationalarchives.gov. uk/20130107105354/http://www.dh.gov.uk/prod_consum_dh/groups/dh_digitalassets/@dh/@en/documents/digitalasset/dh_4062264.pdf.

121. F. Boag and F. Kelly, "Screening for Chlamydia trachomatis," editorial, British Medical Journal 316 (1998): 1474.

122. J. M. Pimenta et al., "Opportunistic Screening for Genital Chlamydial Infection II: Prevalence among Healthcare Attenders, Outcome, and Evaluation of Positive Cases," Sexually Transmitted Infections 79 (2003): 22-27. See also 
M. Catchpole et al., "Chlamydia Screening in the United Kingdom," Sexually Transmitted Infections 79 (2003): 3-4.

123. D. S. LaMontagne et al., "Establishing the National Chlamydia Screening Programme in England: Results from the First Full Year of Screening," Sexually Transmitted Infections 80 (2004): 335-41.

124. R. Jones and F. Boag, "Screening for Chlamydia trachomatis," editorial, British Medical Journal 334 (2007): 703.

125. N. Low, "Screening Programmes for Chlamydial Infection: When Will We Ever Learn?," British Medical Journal 334 (2007): 72. Low's evidence for a new view of the natural history of chlamydia infection drew on A. J. Boeke et al., "The Risk of Pelvic Inflammatory Disease Associated with Urogenital Infection with Chlamydia trachomatis: Literature Review," Nederlands Tijdschrift voor Geneeskunde 149 (2005): 878-84. See also N. Low et al., "Epidemiological, Social, Diagnostic, and Economic Evaluation of Population Screening for Genital Chlamydial Infection," Health Technology Assessment 11 (2007), http://dx.doi.org/10.3310/hta11080; L. A. Wallace et al., "What Is the Excess Risk of Infertility in Women after Genital Chlamydia Infection? A Systematic Review of the Evidence," Sexually Transmitted Infections 84 (2008): 171-75; and J. A. Land et al., "Epidemiology of Chlamydia trachomatis Infection in Women and the Cost-Effectiveness of Screening," Human Reproduction Update 16 (2010): 189-204.

126. N. Low et al., "Screening for Genital Chlamydia Infection," Cochrane Database Systemic Review 12 (2013): 1-15. See also M. H. Ahmadi et al., "Association of Chlamydia trachomatis with Infertility and Clinical Manifestations: A Systematic Review and Meta-analysis of Case-Control Studies," Infectious Diseases 48, no. 9 (2016): 517-23.

127. S. Menon et al., "Human and Pathogen Factors Associated with Chlamydia Trachomatis-Related Infertility in Women," Clinical Microbiological Reviews 28 (2015): 978-79. 